\title{
Examination of Reducing Agents Used for Aluminum Electroless Deposition
}

\author{
Kohei Makino $^{\text {a }}$, Daisuke Marumoto ${ }^{\text {a }}$, Setsuko Koura ${ }^{\mathrm{a}}$. \\ a Department of Applied Chemistry, Chiba Institute of Technology \\ Narashino-city, Chiba 275-0016, Japan
}

\begin{abstract}
Because of its properties such as low electrical resistance, simple to structure in dry etch processes, aluminum is widely used for wiring material in the field of semiconductors. However, in order to deposit aluminum on a silicon substrate, it is necessary to use a sputtering or glow plasma method, and thus a large apparatus is required. If the technique of electroless deposition of aluminum is established, it will be able to obtain the thin film on the silicon substrate easily without electricity. In this research, we performed constant current and electroless aluminum deposition on various semiconductor substrates and evaluated the possibility of $\mathrm{Al}$ electroless deposition on semiconductor wiring. As a result of evaluation by SEM XRD promising results were obtained, and a new reducing agent was discovered that can significantly reduce the time for electroless deposition.
\end{abstract}

\section{Introduction}

In semiconductor products, $\mathrm{Al}$ is used for wiring. However, the glow plasma method and the sputtering method are used for this wiring, and the necessary equipment is very expensive. Electronics industry is demanding the development of lower cost wiring technology. Therefore, attention has been paid to the electroless deposition of $\mathrm{Al}$ using an ionic liquid that can deposit Al. The success of electroless Al deposition using $66.7 \mathrm{~mol} \%$ $\mathrm{AlCl}_{3}+33.3$ mol\% EMIC ionic liquid and glass substrate has already been reported ${ }^{12) 3}$.

In this research, constant current electrolysis and electroless deposition were used to deposit $\mathrm{Al}$ on the silicon substrate coated with tungsten (W) or with titanium nitride (TiN) which had not been reported so far, and $\mathrm{Al}$ was investigated by X-ray diffraction (XRD), scanning electron microscopy (SEM). We also studied a new reducing agent that can reduce the plating time for electroless $\mathrm{Al}$ deposition, and actually performed electroless $\mathrm{Al}$ deposition using the discovered reducing agent.

\section{Experimental}

Electrochemical deposition on silicon substrate coated with $\mathrm{W}$ and with TiN

Degreasing and pickling: Silicon substrates coated with $\mathrm{W}$ and TiN were degreased with $5 \%$ sodium hydroxide solution for 3 minutes and pickled with $5 \%$ hydrochloric acid solution for 2 minutes. The pretreatment of the electrodes in the subsequent experiments was also performed by the same method. 
Electrochemical deposition and analysis: A bipolar cell was used, and silicon substrate coated with $\mathrm{W}$ and with TiN, which had a reaction area of $1 \mathrm{~cm}^{2}$ masked with Nitoflon tape, was used as a working electrode, and an $\mathrm{Al}$ electrode was used as a counter electrode. Ionic liquid of $66.7 \mathrm{~mol} \% \mathrm{AlCl}_{3}+33.3 \mathrm{~mol} \%$ EMIC was used as electrolyte and deposition was performed at constant current ${ }^{4) 5}$. Next, the deposited Al was analyzed by SEM and XRD. Further, all the work relating to electrochemical deposition and electroless deposition was performed inside the glove box.

Electroless deposition on each substrate using di-isobutyl aluminum hydride (DIBAH) reducing agent

Applying catalyst to the substrate: In order to perform electroless $\mathrm{Al}$ deposition, silicon substrate coated with $\mathrm{W}$ and with TiN were degreased and pickled, and then immersed in a palladium (Pd) solution having a concentration of $125 \mathrm{mg} / \mathrm{L}$ to apply a catalyst. Then, it was dried with cold air.

Implementation of electroless plating: Electroless $\mathrm{Al}$ deposition is performed by dissolving $10 \mathrm{ml}$ of $1.0 \mathrm{~mol} / \mathrm{l}$ DIBAH reducing agent in $40 \mathrm{ml}$ of $66.7 \mathrm{~mol} \% \mathrm{AlCl}_{3} 33.3$ mol\% EMIC ionic liquid heated to $70{ }^{\circ} \mathrm{C}$ and immersing a silicon substrate coated with W and TiN.

\section{Examination of new reducing agents}

Degreasing and pickling of electrodes: $\mathrm{W}$ plate, $\mathrm{Al}$ plate and $\mathrm{Al}$ wire were degreased and pickled with $5 \%$ sodium hydroxide solution and $5 \%$ hydrochloric acid solution.

Self-potential measurement: We conducted linear sweep voltammetry measurements to investigate new reducing agents. The measurement was performed in a 3-electrode cell, $\mathrm{W}$ electrode as the working electrode, $\mathrm{Al}$ electrode as the counter electrode, and an aluminum wire $(99.99 \%, \varphi: 2 \mathrm{~mm})$ immersed in a $66.7 \mathrm{~mol} \% \mathrm{AlCl}_{3}+33.3 \mathrm{~mol} \%$ EMIC melt in a Pyrex tube separated by a G4 glass frit was used as the reference electrode. The electrochemical behavior of reducing agents in $50 \mathrm{~mol} \% \mathrm{AlCl}_{3}+50 \mathrm{~mol} \%$ EMIC ionic liquid was investigated.

\section{Al deposition using the newly discovered reducing agent}

Electroless plating with discovered reducing agent: Al electroless deposition was performed on the silicon substrate coated with $\mathrm{W}$ using the discovered reducing agent. deposition was performed under two conditions when reducing agent A was dissolved in the electrolyte as it was, and when it was dissolved in a solvent and the concentration was adjusted. We confirmed the possibility of $\mathrm{Al}$ precipitation, the deposition time and the effect of hydrogen generated during the deposition reaction.

\section{Electrochemical deposition}

\section{Results and Discussion}

State of deposited Al: Electrochemical deposition was performed in $\mathrm{AlCl}_{3} 66.7 \mathrm{~mol} \%+$ EMIC $33.3 \mathrm{~mol} \%$ ionic liquid, and an $\mathrm{Al}$ film could be obtained on silicon substrate coated 
with $\mathrm{W}$ and with TiN. The state of the surface after Al electrochemical deposition is shown in Figure 1. Al deposition was visually confirmed on all substrates. The Al film was analyzed using SEM. The SEM image is shown in Figure 2. From SEM and visual observation, it was found that an Al film could be deposited on either substrate. In the case of silicon substrate coated with TiN, its smoothness was remarkable.

(a)

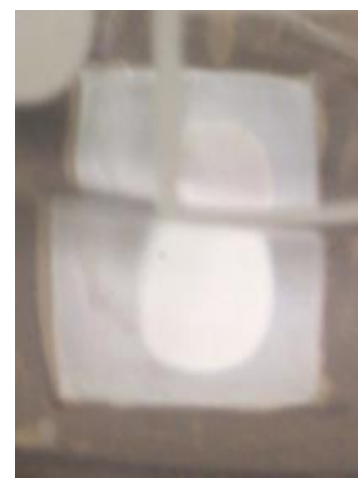

(b)

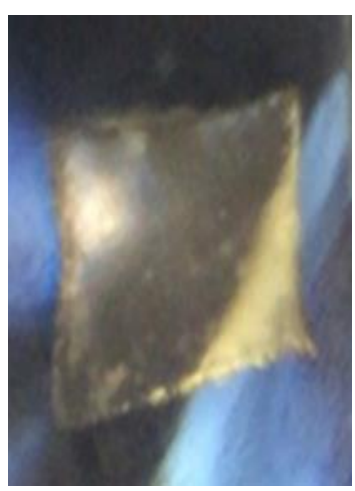

(a)

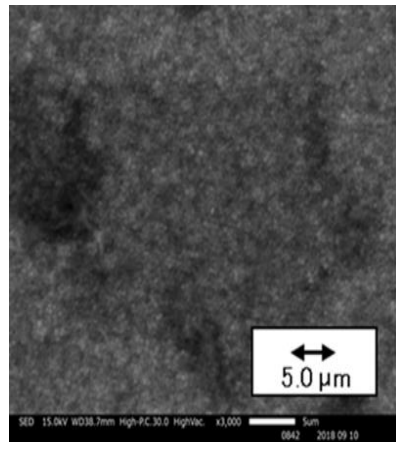

(b)

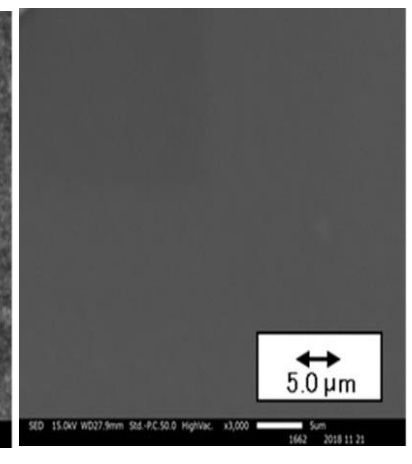

Figure 1. Al deposited on the substrate by electrochemical deposition. (a) silicon substrate coated with W, (b) silicon substrate coated with TIN
Figure 2. SEM images of Al deposited on various substrates. (a) silicon substrate coated with W, (b) silicon substrate coated with TiN

Analysis of deposited Al by XRD: XRD confirmed clear peaks derived from the $\left(\begin{array}{lll}1 & 1 & 1\end{array}\right)$ $\left(\begin{array}{lll}2 & 0 & 0\end{array}\right)\left(\begin{array}{lll}2 & 2 & 0\end{array}\right)\left(\begin{array}{lll}3 & 1 & 1\end{array}\right)$ planes of $\mathrm{Al}$ on silicon substrate coated with W. Even in the case of silicon substrate coated with TIN, a peak derived from Al was confirmed although it was not as clear as that of silicon substrate coated with W. The results are shown in Figure 3. From these results, it was found that Al was deposited without problems even with silicon substrate coated with $\mathrm{W}$ and with TiN.

(a)

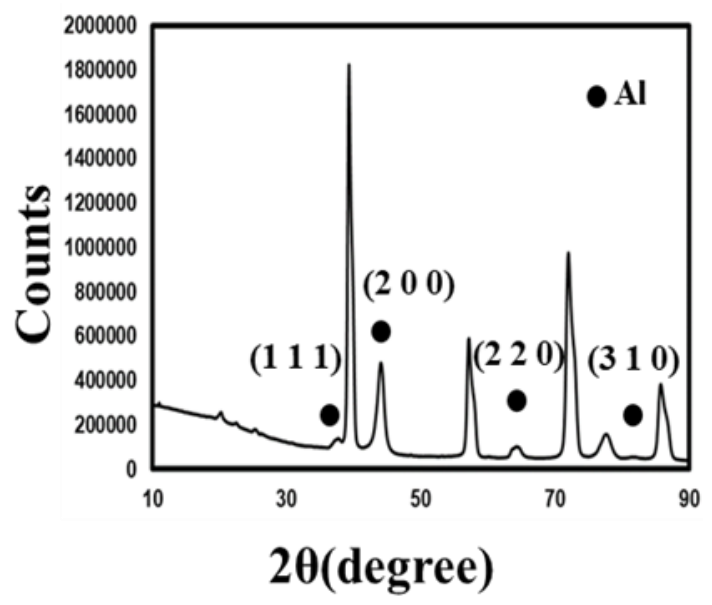

(b)

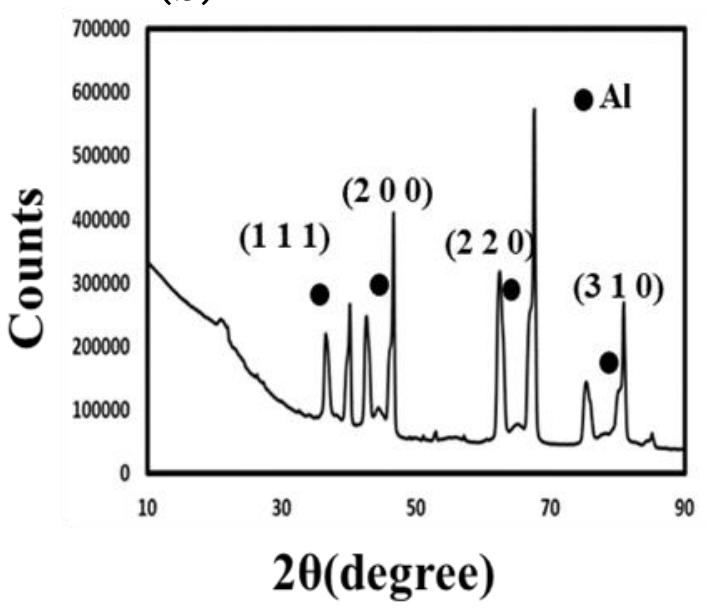

Figure 3. XRD of Al deposited on various substrates. (a) silicon substrate coated with W, (b) silicon substrate coated with TIN 


\section{Electroless deposition with DIBAH reducing agent}

Electroless deposition on silicon substrate coated with W and with TiN: Figure 4 shows the result of electroless Al deposition on silicon substrate coated with $\mathrm{W}$ and with TiN using DIBAH reducing agent. Al deposition film was deposited by the reaction shown in Equations 1 and 2 on a silicon substrate coated with $\mathrm{W}$ and TiN from $66.7 \mathrm{~mol} \% \mathrm{AlCl}_{3}$ $+33.3 \mathrm{~mol} \%$ EMIC ionic liquid containing DIBAH reducing agent. However, it took more than 6 hours to form the Al film. In addition, the surface condition was very rough, and many unprecipitated parts were confirmed. It is thought that this is caused by the generation of hydrogen on the substrate surface during electroless deposition according to reaction formula 1. From these results, it was found that a reducing agent that has a fast reaction rate and does not generate hydrogen is required for rapid electroless deposition of $\mathrm{Al}$ and smoothing the deposited film.

(a)

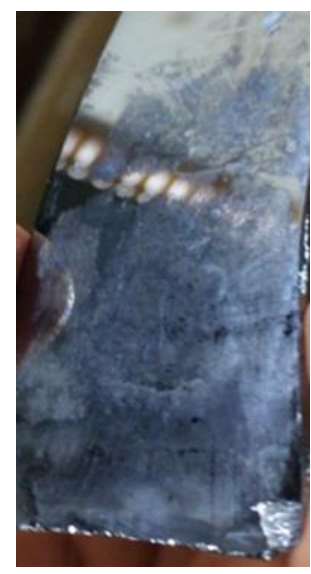

(b)

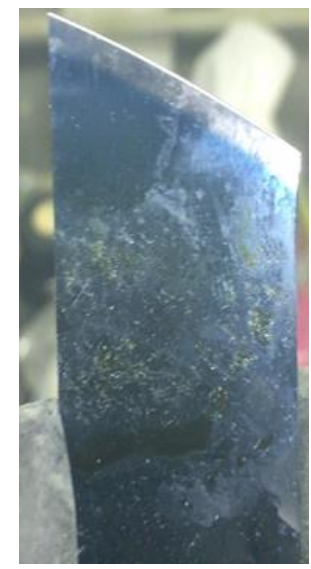

Figure 4. Al electroless deposition for each substrate. (a) silicon substrate coated with W, (b) silicon substrate coated with TiN

$\left(\mathrm{CH}_{3}\right)_{2}-\mathrm{CH}-\mathrm{CH}_{2}-\mathrm{AlH}-\mathrm{CH}_{2}-\mathrm{CH}-\left(\mathrm{CH}_{3}\right)_{2} \rightarrow\left(\mathrm{CH}_{3}\right)_{2}-\mathrm{CH}-\mathrm{CH}_{2}-\mathrm{Al}^{+}-\mathrm{CH}_{2}-\mathrm{CH}-\left(\mathrm{CH}_{3}\right)_{2}+(\mathbf{1} / 2) \mathrm{H}_{2}+\mathrm{e}$ [1]

$$
\mathrm{Al}_{2} \mathrm{Cl}_{7}^{-}+3 \mathrm{e} \rightarrow 7 \mathrm{AlCl}_{4}^{-}+\mathrm{Al}
$$

New reducing agent for $\mathrm{Al}$ electroless deposition

Results of linear sweep voltammetry: We investigated a new reducing agent to solve the problem that film formation takes time. Some reducing agents showed less-novel potential, indicating that they can be used as a reducing agent as well as DIBAH for electroless Al deposition. The results of linear sweep voltammetry measurements of various reducing agents are shown in Table 1. Among these reducing agents, reducing agent A was particularly promising in terms of reaction rate and suppression of hydrogen generation. 
TABLE I. self-potential of each reducing agent

\begin{tabular}{cccc}
\hline Reducing agent & Potential(V) & Reducing agent & Potential(V) \\
\hline DIBAH & -0.49 & $\mathrm{C}_{3} \mathrm{H}_{6} \mathrm{O}_{3}$ & +0.12 \\
Reducing agent A & -0.31 & $\mathrm{KBH}_{4}$ & +0.17 \\
Reducing agent B & -0.58 & $\left(\mathrm{CH}_{3}\right)_{2} \mathrm{NH} \cdot \mathrm{BH}_{3}$ & +0.15 \\
$\mathrm{FeCl}_{2}$ & +0.23 & $\mathrm{NaBH}_{4}$ & +0.34
\end{tabular}

Electroless deposition using reducing agent $\mathrm{A}$

Directly add reducing agent $\mathrm{A}$ to the deposition solution: When the reducing agent $\mathrm{A}$ was directly dissolved in the deposition solution, no Al film was obtained, probably because the reactivity of the reducing agent was so strong that it reacted with the deposition solution immediately after dissolution.

Dissolve in solvent and adjust concentration: When reducing agent A was dissolved in a solvent to adjust the concentration and electroless Al deposition was performed, a deposition film was obtained. Figure 5 shows the condition of the board before and after deposition. The deposition of Al was confirmed on the substrate, and the deposition speed was extremely fast, reducing the deposition time from 6 hours to a few minutes.

Furthermore, compared to the case where the DIBAH reducing agent shown in Figure 4 was used, there were few unprecipitated parts and an $\mathrm{Al}$ film could be obtained over the entire surface. It is considered that this is because hydrogen is not generated during the deposition reaction due to the nature of the reducing agent A. From these results, it was found that the reducing agent $\mathrm{A}$ can be used for electroless deposition of $\mathrm{Al}$, the deposition time can be significantly shortened, and the smoothness of the deposited film can be improved. Also, it was very important to control the reactivity by adjusting the concentration of the reducing agent.
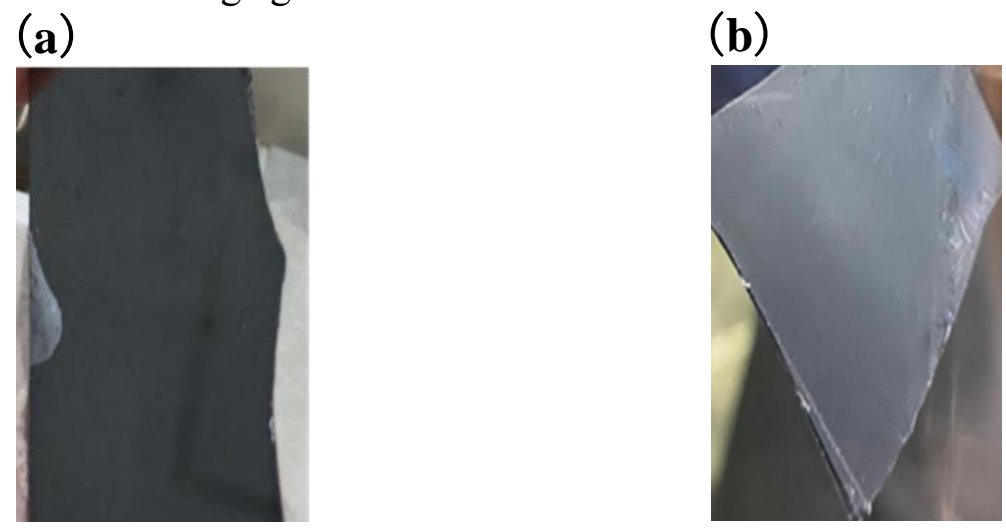

Figure 5. State after electroless deposition using reducing agent A. (a) Before deposition silicon substrate coated with W, (b) After deposition silicon substrate coated with W 


\section{Conclusion}

Through electrochemical deposition experiments, it was found that Al could be deposited on the surface without problems even with silicon substrate coated with $\mathrm{W}$ and with TiN. Experiments on electroless deposition have revealed that electroless deposition is possible on silicon substrate coated with $\mathrm{W}$ and with TiN when $\mathrm{AlCl}_{3} 66.7 \mathrm{~mol} \%+\mathrm{EMIC} 33.3 \mathrm{~mol} \%$ plating solution and DIBAH reducing agent are used. However, exfoliation and nonprecipitation occur due to the generation of hydrogen originating from the reducing agent. We discovered two new chemicals that could be used as reducing agents by linear sweep voltammetry. As a result of performing electroless $\mathrm{Al}$ deposition using reducing agent $\mathrm{A}$, it was possible to reduce the deposition time, which took 6 hours or more, to a few minutes,

and it was not confirmed that hydrogen was generated during deposition. Application of electroless $\mathrm{Al}$ deposition using reducing agent $\mathrm{A}$ with excellent properties to semiconductor wiring is expected.

\section{References}

1. Setsuko Koura, Souta Ooshima, Daiki Kudo, Electroless deposition of Aluminum from a Room Temperature Ionic Liquid Electrolyte, 2016 / 230th ECS Meeting Electrochemical Society (USA and Japan) (2016)

2. N. Koura, H. Nagase, A. Sato, S. Kumakura, K. Takeuchi, K. Ui and C.K. Loong ; J. Electrochem. Soc., 155, D155 (2008).

3. I. Shitanda, A. Sato, M. Itagaki, K. Watanabe and N. Koura ; Electrochim. Acta, 54, 5889 (2009).

4. S. Takahashi, K. Akimoto and I. Saeki ; J. Surf. Finish. Soc. Jpn., 40, 548 (1989).

5. S. Takahashi, L.A. Curtiss, D. Gosztola, N. Koura, Marie-Louise Saboungi, Inorg. Chem., 34, 2990 (1995) 